\title{
Forward and backward associations in RI-PI differences'
}

\author{
MARTIN S. LINDAUER, DEPARTMENT OF PSYCHOLOGY \\ STATE UNIVERSITY OF NEW YORK, COLLEGE AT \\ BROCKPORT, Brockport, N. Y. 14420
}

The difference between retroactive and proactive inhibition (RI-PI) was investigated after $A-B, A-C$ and $A-B, C-D$ paradigms of learning, and forward and backward tests of recall. $R I$ was generally worse than PI, irrespective of either the interference or recall conditions. These results, together with the finding of backward learning, were taken as support of a symmetrical view of the association process.

The relative strengths of forward and backward associations have been subject to various estimations and interpretations (Ekstrand, 1966). The RI-PI difference, interpreted by two-factor theory (Postman, 1961) as due to the differential strength of the unlearned forward RI association in relation to PI, has received little attention in this connection (Lindauer, 1967). In the present study, the strength of the associations in RI were varied through the type of interference and the direction of recall used, with the expectation that the RI-PI difference would change accordingly. Thus A-C interference should yield RI under forward but not backward recall tests (Barnes \& Underwood, 1959; Keppel \& Underwood, 1962) and C-D interference should yield less RI than A-C (McGovern, 1964). In addition, the competition between responses responsible for PI (Melton \& von Lackum, 1941) should also vary under these conditions.

Method. Ten groups of Ss learned a list of paired-associates (OL) to a criterion of one errorless trial. Eight work groups were then immediately presented with 10 trials of an interfering paired-associate list (IL/PL): four groups in the RI condition received IL after OL; and four groups in the PI condition received PL before OL. Two each of the groups in the RI and PI conditions had the A-B, A-C paradigm of learning and two each had the A-B, $C$-D paradigm. Two Control groups learned only OL. The material was presented at a 2:2 rate, with a 8 -sec intertrial interval. All groups received five trials of either a forward (S-R) or backward (R-S) recall (first trial)/relearning (RL) test of OL $30 \mathrm{~min}$ after the end of OL. In R-S recall/RL, Ss were presented with the responses of OL and asked to anticipate the stimuli of OL. The various combinations of transfer designs and recall techniques used are abbreviated as follows: the first letter after a condition designation refers to the similarity (s) or dissimilarity (d) between the stimuli of the two lists; the second letter refers to the forward ( $f$ ) or backward (b) nature of the recall task; e.g., RI-sf designates the RI group which had the A-B, A-C paradigm of learning and the forward recall test.

Four lists of 10 pairs of unrelated two-syllable adjectives, randomly selected from lists in Hilgard (1951, pp. 548-552) were used, and arranged into the two paradigms according to Thune \& Underwood's rules (1943, p. 185). Each of the four lists was used equally in every condition as $\mathrm{OL}$ and as the interfering list; the beginning order during learning was randomly assigned; and the starting order at recall was different from the last order used during $\mathrm{OL}$.

The Ss were 120 female and 40 male volunteer undergraduates, randomly assigned prior to their appearance at the experimental session to 10 groups of 16 Ss each; none had previously served in a verbal learning experiment.

Results. Indicative of a positive transfer effect from previous learning, the PI condition learned OL faster than the RI condition $(F=17.54, \mathrm{df}=1 / 96, \mathrm{p}<.005)$, while the RI condition learned significantly more items than the PI condition by the last trial of interference learning $(F=23.28, \mathrm{df}=1 / 96, \mathrm{p}<.005)$. In neither case was the superiority of learning related to the similarity characteristics of previous learning $(F<1)$. Taking these differences in $O L$ into account in examining the recall/RL data (Table 1), an analysis of co-variance showed that the PI condition retained more than the $\mathrm{RI}$ condition in recall $(\mathrm{F}=18.24$, $\mathrm{df}=$ $9 / 149, p<.005)$ and on each RL trial as indicated by the absence of a trials by conditions interaction $(F=1.02, \mathrm{df}=21 / 360, \mathrm{p}>$ .05). In addition, not only was there no difference between the recall data for slow vs fast learners on $\mathrm{OL}(\mathrm{F}=1.33, \mathrm{df}=1 / 112, \mathrm{p}$ $>.05)$, but these differences in rate of learning did not confound the difference found between RI and PI $(F<1)$. Each of the PI groups during recall, except for the PI-db/RI-db difference which was in the right direction but not significant $(t=1.22, \mathrm{df}=30, \mathrm{p}$ $>.05$ ), was significantly better than its corresponding RI group. (Based on an error variance $=0.57$, from the analysis of variance, and using adjusted means based on the within-group regression coefficient $=0.04$ (Lindquist, 1956, p. 327), t's ranged from 2.07 to $3.41, p<.05$.) In RL, although all differences between RI and PI groups were in the expected direction, only PI-sf remained significantly better than RI-sf $(p<.05)$. The superiority of the PI condition was also manifested by the significantly greater number of Ss (44 as compared with 33 in the RI condition) who successfully recalled all items in five or fewer trials $\left(\chi^{2}=3.94\right.$, df $=1, \mathrm{p}<.05$ ).

The difference between RI and PI was not affected by the direction of the recall test, whether forward or backward, in recall or $\mathrm{RL}(\mathrm{F}<1)$; or by the nature of the interference conditions, whether similar or dissimilar, in both recall $(F=2.68, \mathrm{df}=1 / 96, \mathrm{p}$ $>.05)$ and $\mathrm{RL}(\mathrm{F}=1.16$, df $=1 / 96, \mathrm{p}>.05)$. The forward direction was better than the backward direction in both recall ( $F$ $=92.16, \mathrm{df}=1 / 96, \mathrm{p}<.005)$ and $\mathrm{RL}(\mathrm{F}=33.41, \mathrm{df}=1 / 96, \mathrm{p}<$ $.005)$. This was true of all forward recall groups, and with the exception of the RI-sf/RI-sb comparison, of all groups in RL. The characteristics of the interfering list as such, whether similar or dissimilar to $\mathrm{OL}$, did not affect recall $(\mathrm{F}=3.50, \mathrm{df}=1 / 96, \mathrm{p}>$ .05); a dissimilar interference list did lead to better RL than did a similar list $(\mathrm{F}=5.29, \mathrm{~d} f=1 / 96, \mathrm{p}<.02)$, but this was contributed by just one comparison, RI-sf/RI-df. However, direction of recall was not independent of the nature of interference learning in both recall $(F=19.79$, df $=1 / 96, p<.005)$ and $R L(F=6.32, \mathrm{df}=$ $1 / 96, \mathrm{p}<.05$ ); while forward recall/RL was better after dissimilar rather than similar interference learning, the opposite was true under backward recall/RL conditions.

Control-f was significantly better than the two forward RI groups in both recall and $\mathrm{RL}(\mathrm{t}=3.68$, df $=46, \mathrm{p}<.01$; Lindquist, 1956, p. 214); this was also true of the PI-sf group $(\mathrm{t}=$ $2.69, \mathrm{df}=30, \mathrm{p}<.02$ ) during recall only.

Discussion. The RI-PI difference did not vary as a function of the direction of recall or the nature of the interfering lists in both recall and RL. This unchanging relationship is also. shown by the lack of a difference between corresponding sets of RI-PI comparisons: for the forward recall sets, RI-sf/PI-sf vs RI-df/PI-df(t $=0.20, \mathrm{df}=60, \mathrm{p}>.05)$; and for the backward recall sets, RI-sb/PI-sb vs RI-db/PI-db(t $=0.46, d f=60, p>.05)$ (Edwards, 1960, pp. 140-144). Assuming the symmetry of forward and backward associations (Asch \& Ebenholtz, 1962), the data indicates that unlearning and competition factors responsible for the RI-PI difference in forward recall are not independent of the backward associations formed. Indicating backward learning (Richardson, 1960) is the finding that while forward recall was better than backward, backward recall was better when the interference was similar. The R-S recall of the A-term of A-C, unlike that of the C-term of C-D, was facilitated by backward learning concurrent with forward learning. The lack of significant differences between the controls and several work groups tends to qualify this discussion of the relatively equal strengths of forward and backward associations somewhat, since a difference between RI and PI would

Table 1

Mean Number Correctly Recalled (Trial 1) and Relearned (Trials 2-5)

\begin{tabular}{|c|c|c|c|c|c|c|c|c|c|}
\hline \multirow[b]{3}{*}{ Group } & \multicolumn{4}{|c|}{ Forward } & \multicolumn{5}{|c|}{ Backward } \\
\hline & \multicolumn{2}{|c|}{ Recall } & \multicolumn{2}{|c|}{ RL } & \multirow[b]{2}{*}{ Group } & \multicolumn{2}{|c|}{ Recall } & \multicolumn{2}{|c|}{ RL } \\
\hline & M & SD & $\mathbf{M}$ & SD & & $\mathbf{M}$ & SD & $\mathbf{M}$ & SD \\
\hline RI-sf & 5.56 & 1.13 & 8.24 & 1.15 & RI-sb & 4.25 & 2.22 & 7.79 & 1.27 \\
\hline PI-sf & 7.31 & 1.12 & 9.06 & 0.82 & PI-sb & 5.88 & 1.72 & 8.39 & 0.98 \\
\hline RI-df & 7.63 & 1.19 & 9.34 & 0.65 & RI-db & 4.06 & 1.57 & 7.84 & 1.12 \\
\hline PI-df & 8.63 & 0.63 & 9.61 & 0.41 & PI-db & 4.69 & 1.60 & 8.26 & 1.35 \\
\hline Control-f & 8.44 & 1.26 & 9.56 & 0.60 & Control-b & 5.00 & 2.24 & 8.17 & 1.74 \\
\hline
\end{tabular}


ordinarily require RI and PI effects (but see Osgood, 1956, pp. 521-522). However, with backward learning facilitating recall in the $\mathrm{A}-\mathrm{C}$ groups, which also had an additional exposure to the recall items during learning (Houston, 1964), and the C-D groups having the advantage of list differentiation (Underwood, 1945), the control data may be considered irrelevant to the critical fact that RI and PI were nonetheless different from each other.

\section{REFERENCES}

ASCH, S. E., \& EBENHOLTZ, S. M. The principle of associative symmetry. Proc. Amer. Phil. Soc, 1962, 106, 135-163.

BARNES, J. M., \& UNDERWOOD, B. J. "Fate" of first-list associations in transfer theory. J. exp. Psychol, 1959, 58, 97-105.

EDWARDS, A. L. Experimental design in psychological research, (rev. ed.). New York: Rinehart, 1960.

EKSTRAND, B. R. Backward associations. Psychol. Bull., 1966, 65(1), 50-64.

HILGARD, E. R. Methods and procedures in the study of learning. In S. S. Stevens (Ed.), Handbook of experimental psychology. New York: Wiley, 1951.

HOUSTON, J. P. Verbal R-S strength following S-R extinction. Psychon. Sci, 1964, 1, 173-174.

KEPPEL, G., \& UNDERWOOD, B. J. Retroactive inhibition of R-S associations. J. exp. Psychol, 1962, 64(4), 400-404.

LINDAUER, M. S. RI and PI after R-S recall of overlearned material.
Psychon. Sci, 1967, 9(6), 341-342.

LINDQUIST, E. F. Design and analysis of experiments in psychology and education. Boston: Houghton Mifflin, 1956.

McGOVERN, J. B. Extinction of associations in four transfer paradigms. Psychol Monogr., 1964, 78(16, Whole No. 593).

MELTON, A. W., \& von LACKUM, W. J. Retroactive and proactive inhibition in retention: Evidence for a two-factor theory of retroactive inhibition. Amer. J. Psychol, 1941, 54, 157-173.

OSGOOD, C. E. Method and theory in experimental psychology. New York: Oxford, 1956.

POSTMAN, L. The present status of interference theory. In C. N. Cofer (Ed.), Verbal leaming and verbal behavior. New York: McGraw-Hill, 1961.

RICHARDSON, J. Comparison of S-R and R-S learning of paired associates. Psychol Rep., 1960, 7, 225-228.

THUNE, L. E. \& UNDERWOOD, B. J. Retroactive inhibition as a function of degree of interpolated learning. J. Psychol., 1943, 32, 185-200.

UNDERWOOD, B. J. The effect of successive interpolation on retroactive and proactive inhibition. Psychol. Monogr., 1945, 59, No. 3.

NOTE

1. Part of the research was supported by a Public Health Service Grant No. 17,461. Data were collected at Cedar Crest College. Dr. H. Gleitman provided valuable assistance on earlier versions of this manuscript. 